\title{
Construction and demolition waste management in China: analysis of economic instruments for solving a growing problem
}

\author{
W. Zhao ${ }^{1}$, R. B. Leeftink ${ }^{2} \&$ S. Rotter ${ }^{3}$ \\ ${ }^{I}$ Chongqing University, \\ Institute of Construction Management and Real Estate, China \\ ${ }^{2}$ Decistor bv, Netherlands \\ ${ }^{3} T U$ Berlin, Institute of Environmental Engineering, Germany
}

\begin{abstract}
The Chinese government has made a clear commitment to achieve a minimum of $15.5 \mathrm{~m}^{2}$ of living space per person by 2010 . The consequent large quantity of construction and demolition waste (C\&DW) has placed great burden on the finite landfill space and environmental protection. The objectives of this paper are:

a) To outline the trend of C\&DW generation in China;

b) To indicate different actors in the waste management "chain", each with their own economic objectives and constraints;

c) To introduce an economic decision making model to predict economic behaviour of different actors and some of their interactions;

d) To explore governmental instruments and their potential influence on waste market actors;

e) To evaluate the effectiveness of some economic instruments (tax on landfill and raw materials, subsidy for recyclers and their combination).

In this paper a model is presented to predict waste flows, based on an explanation of the behaviour of actors, each taking decisions based on respective cost and benefit of different disposal possibilities. Policy instruments are discussed by analyzing the feedback of actors on different instruments. A process of integrated waste strategy should be considered based on respective strength and weakness of instruments: Subsidy for fostering recycling industry $\rightarrow$ Combination to lighten financial burden by revenue of tax $\rightarrow$ Tax with comprehensive regulation system $\rightarrow$ Self-determination of recycling market.
\end{abstract}

Keywords: construction and demolition waste $(C \& D W)$, economic instruments, waste management, China. 


\section{Introduction}

The Chinese government has made a clear commitment to achieve a minimum of $15.5 \mathrm{~m}^{2}$ of living space per person by 2010 for improving the standard of living after the post-reforms initiated in early 1980s [1]. To achieve this goal, since the early 1980s, urban China has been changing rapidly with a massive housing development program together with a heavy infrastructure construction schedule (shown in fig.1). Fastigium of C\&DW generation will be coming after 30-40 years, which is the life time of current buildings. In recent years, civil engineering wastes have reached $30-40 \%$ of the total city waste because of the large-scale construction and buildings demolition, which results from the accelerating urbanization and city rebuilding [2]. The large quantity of C\&DW has placed great burden on the finite landfill space and environmental protection. In the current recycling market in China only small amounts of valuable materials like copper and steel are reused or recycled, whereas large amounts of materials like concrete are directly transported into the C\&D landfills, because no profit can be made. The current market is a significant obstacle for C\&DW management in China.

The main objectives of this paper are:

a) To indicate different actors in the waste management "chain", each with their own economic objectives and constraints;

b) To introduce an economic decision making model to predict economic behaviour of different actors and some of their interactions;

c) To explore governmental instruments and their potential influence on waste market actors;

d) To evaluate the effectiveness of some economic instruments (tax on landfill and raw materials, subsidy for recyclers and their combinations).

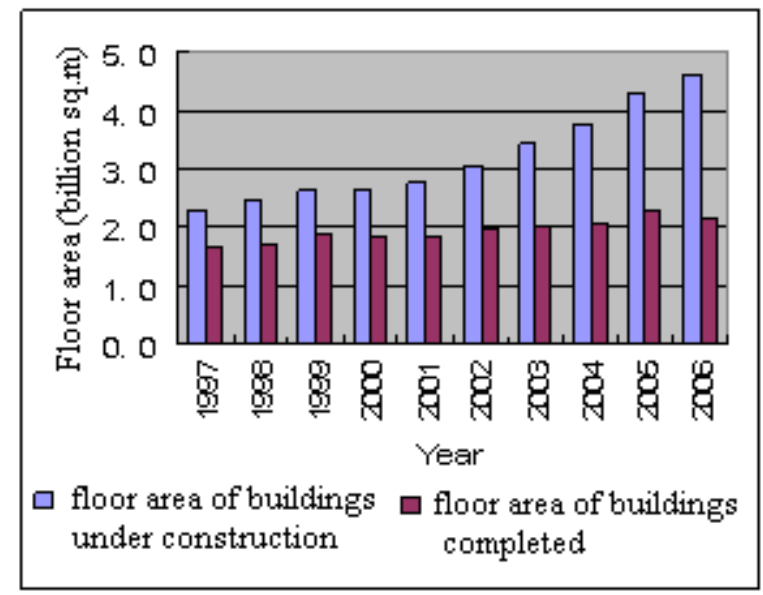

Figure 1: $\quad$ Trend of floor area of building from the China yearbook 19982007 [3]. 


\section{Background information}

\subsection{Description of actors in the waste management "chain"}

The waste market is like an arena with many actors, each with their own economic objectives and constraints. Decision of waste flow is formulated based on respective cost and benefit of disposal for quantitative analysis of economic behaviors of actors in this paper.

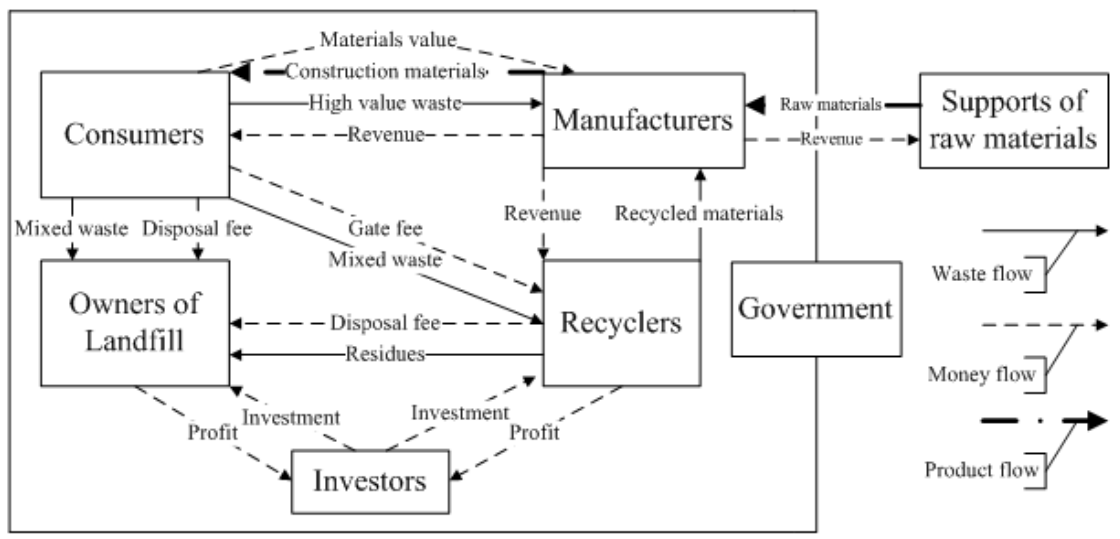

Figure 2: Interactions of actors influenced by waste and money flow.

Fig. 2 indicates the interrelationship among actors. Cost of one actor might be the revenue of another, for example disposal cost of waste producers becoming income of landfills and recyclers, material costs of manufacturers as revenue of waste producers and recyclers. Total revenue of waste management consists of disposal cost of waste producers and intrinsic value of waste determined by manufacturers.

\subsubsection{Consumers}

Consumers mean the primary waste producers, including contractors of construction, renovation and demolition in construction industry as well as households who produce decorative waste. Considering four disposal approaches (recycling facilities, illegal dumping, landfill and recycling on site,), per unit cost of disposal will influence final decision of consumers. Cost of recycling facilities contains transporting cost to recycling facilities per ton $(T r)$, the gate fee to recycling facilities per ton $(G f)$, extra costs to recycling facilities per ton $(E r)$ like separation cost on site if the recycling facilities don't accept mixed waste. Cost of illegal dumping contains costs for loading, transportation as well as risk cost for non compliment per ton $(I p)$. Cost of recycling on site contains the difference between the separation cost of waste on site and transportation cost to manufacturers per ton $(S c)$, revenue of waste selling per ton $(R v)$. Cost of landfill includes transporting cost to landfill site per ton $(T l)$, disposal fee to landfill per 
ton $(D f)$. Equ (1) summarises the decision of the consumers to bring C\&DW to the recycling instead of other options:

$$
T r+G f+E r=\operatorname{Min}(I p, S c-R v, T l+D f, T r+G f+E r)
$$

\subsubsection{Manufacturers}

Manufacturers, who regard potential recycled materials like aggregates as raw materials, are involved in C\&DW management. The manufacturers will use recycled materials only if per unit cost of primary materials exceeds per unit cost of recycled materials. Unit cost of primary materials includes price of raw materials per ton $(P m)$, transportation cost to construction site per ton $(T q)$, and cost of recycled materials consists of any extra costs created by using the recycled product per ton $(E r u)$, price of recycled product per ton $(R C p)$, transportation cost from recycling facilities to site per ton $(\operatorname{Tru})$.

$$
P m+T q>E r u+R C p+T r u
$$

\subsubsection{Recyclers}

Recyclers who are in material recovery include owners of recycling facilities and waste pickers. The total cost of production containing capital costs (crushers, screeners etc) and operating costs (labour, energy, administration) must be divided by the units produced to find unit cost $(R c)$. Acceptable unit profit $(P)$ is also necessary. These must be covered by main revenue from the gate fee to recycling $(G f)$ and the revenue of recycled materials $(R C p)$ if recycling is feasible.

$$
R c+P \leq G f+R C p
$$

\subsubsection{Owners of landfill cites}

Waste flow into landfill won't stop unless revenue from disposal unit fee $(D f)$ exceeds fixed unit cost $\left(F_{c}\right)$ and operational unit costs $(O c)$. While $F_{c}$ includes costs for construction works, equipment and land per ton, and $O c$ includes costs for labour, energy, maintenance and depreciation of equipments per ton.

$$
D f>F c+O c
$$

\subsubsection{Investors}

Investors, who invest in treatment facilities like landfill and recycling centre, come from domestic and overseas companies or individuals as well as government and special organizations like World Bank. For investors, there are two necessary preconditions of investment: ${ }^{1)}$ lifetime of main equipments $(T t)$ surpassing payback period of investment on disposal facilities $(P p) ;{ }^{2)}$ profit $(P)$ exceeding opportunity cost of capital investment with reference to interest of saving $O s$.

$$
L t>P p \text { and } P>O s
$$

\subsubsection{Government}

Here government means the public authorities that are responsible for waste generation, transportation, disposal as well as environmental impact from 
C\&DW. Furthermore, they regulate the activities in waste management. Eco-cost or "community cost" (generation of pollution and deterioration of renewable exceeding natural absorption level and depletion of natural resources) influenced by C\&DW management must be considered for decision making.

\subsubsection{The economic interaction among actors}

Fig. 3 shows priority and key economic references of individual decision of actors. There are two main competition groups: ${ }^{1)}$ owner of landfill and recycler for disposal revenue; ${ }^{2)}$ recycler and support of raw materials for revenue of material selling. In each group, each actor will execute price strategy based on his own cost, with reference to other rivals' price and feedback on his price at the same time. For instance, disposal fee of landfill is established by considering $G f$ to recycling based on landfill cost $(F c+O c)$. Owners of landfill may implement lower price strategy, if recycling cost $(R c)$ is higher than landfill cost. Recycler in two groups is not only a key connecting link between upstream and downstream of waste, but also burden two-tier competition.

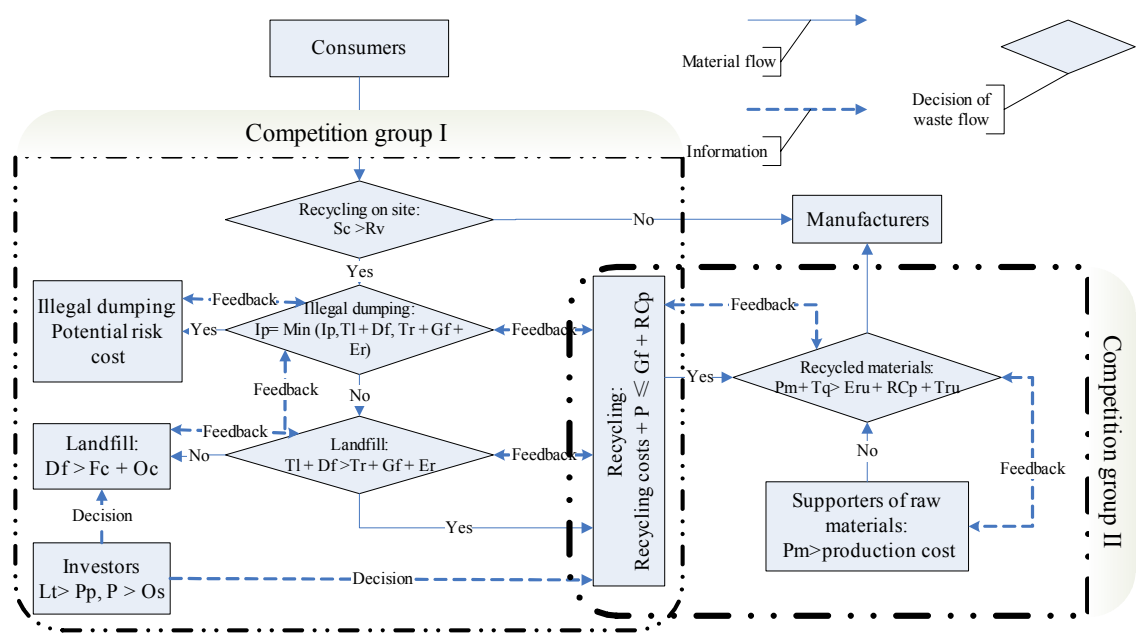

Figure 3: Individual decision of actors based on internal cost and feedback on other rival's price.

Given that the transportation cost is same, behaviour of recyclers is simplified by the following inequation based on equ (1), (2) and (3):

$$
A c+P \leq G+R O p\left\{\begin{array}{l}
G+E<D f \\
R Q p+E u<P m
\end{array}\right.
$$

Government can manage the profit $(P)$ of recycler by controlling disposal fee to landfill $(D f)$ and price of raw materials $(P m)$, eventually regulating waste recycling. From a broad view, disposal cost and recyclable value of waste are two key issues to regulate waste flow through actors in waste management. 


\subsection{Problems of C\&DW management in China}

To explore the feasibility of governmental instruments to manage C\&DW flow in China, the related problems are discussed from a view of economics, because the problems of the actors normally attribute to "money".

\subsubsection{Consumers}

For most consumers, the costs of waste processing are normally less than one percent of their total expenditure. For contractors, especially public contractors, the problems of waste reduction are divided into the following four aspects:

- The architectural design: The special phenomenon in China is concurrence of design and construction. In half of 12 track survey projects, the delay from redesign result in reworking that produce a large amount of construction waste [4].

- The management on the construction site: Due to low price of raw materials and disposal, most managers do not pay attention to improve the level of management on site and establish the standardization of operation for avoiding waste generation.

- The environmental awareness: The contractors consider environmental management as a non-profitable activity. Investigation on construction site in Shenzhen and Hong Kong has been found: $90 \%$ of the respondents think they have no relationship with waste management: only $10 \%$ of the respondents think strengthening waste management is a very significant work [4].

- Recycling and reuse on site: Especially for contractors of demolition, it is not worthy of recycling and reuse if the recycling cost exceeds the recyclable value of waste. Mixed waste will be directly transported into C\&DW landfill for saving cost in case of low tipping fee of landfill.

\subsubsection{Recyclers}

The recycling market lacks a central and stable medium to transform the waste into wealth in China. Unprofessional collection and sorting by waste pickers are difficult for manufactories to find suitable recyclers considering quality and quantity insurance. The current recycling market oriented economy incurs few and profitable materials like steel are reused or recycled, whereas large and nonprofit materials like concrete are directly transported into the C\&D landfills. Weak recycling chains are maintained by spontaneous recycling and reuse of contractors and waste pickers.

\subsubsection{Investors}

Insufficient investment on disposal facilities does not indicate that private investors are not interested in waste recycling industry. It is difficult for investors to afford the high investment costs on facilities, equipments, land and labour in a current recycling environment and market. Changes or ordination in legislation and technical regulation might make the recovery process more expensive. These dynamics make it difficult for the investors to find the right timing and the right 
level for investments. Finally low benefit from recycling aggregates and long payback period stop investment into recycling industry.

\subsubsection{Manufacturers}

The recycled materials are still difficult to be accepted by manufacturers with the consideration of non-quality assurance. An attractive price will make manufacturers change their minds. Nevertheless, consequent low selling revenue will inevitably place great burden on recyclers in case of high recycling cost. The competition in price will ultimately make the recycling chain vanish.

\subsubsection{Owners of landfills}

Although a lot of private landfills exist, public C\&D landfills take dominant capacity of disposal. According to regional regulation like "Commodity Prices issued documents" in a number of cities, disposal fees of urban C\&DW are only 0.2-0.5 EUR per ton excluding transportation. Low disposal fees of landfill lead the waste flow into landfill without recycle. The reasons of low tipping fees are not only non-internal cost from landfill leachate and gas collection system, but also neglected external cost containing land loss and health loss of workers and residents.

\subsubsection{Government}

The Chinese government as two-tier actors (policy maker and investor) plays an essential role in improvement of waste chain and even determination of the future of waste management. The technical and treatment regulations are not distinctly defined. The conservation of resources, minimization of C\&DW from "Construction Law" and "Urban construction waste management" and other regulations are guideline. How to implement it in detail is not involved in laws. For example, recycling C\&DW refers to standardized utilization of original building materials. Furthermore, the regulations and legislations related to environmental matters are too liberal. It will incur waste producers are reluctant to implement the high-investment environmental management measures. Limited financial support will further constrain development of waste management. In addition, "government" is defined as a cooperative administration special for C\&DW at national and local levels in this paper, since three current responsible governmental agencies (Construction committee, Municipal administration commission and Environmental protection administration) are responsible for waste management on site, waste transportation and waste disposal, respectively.

\section{Evaluation on effectiveness of governmental instruments}

\subsection{Description of alternative instruments}

The different instruments for influencing waste management are [5]:

- Technical regulations (IPPC, BAT)

- Treatment regulations (BREF's)

- Economic measurements: subsidies, grants, taxes 
In fact, the effect of technical regulations transforms the external cost into a part of the production cost in every loop of waste flow. The external cost will decrease under better environment and labour conditions by influence of technical regulations. Therefore, these regulations increase the prices of construction products through increase of waste disposal cost. Consumers will have to pay for this increase in the end.

Concerning treatment regulations, bans and setting constraints on waste carried into landfills, policymakers influence the waste chain downstream. However, in current waste market in China, sudden high gate fee of recycling will definitely attract much investment into recycling industry. In the end, it will result in many bankrupts caused by over-competition. Even in waste market of developed countries like Netherlands, government will also meet a lot of lobbyists from the waste industry that might be either for or against measurements depending on their own benefits in the industry.

Economic instruments are considered as more effective tools to manage actors' decision than other government instruments by mean of a direct effect on their cost and revenue, because of the close economic interaction among actors in waste chain. Once economic instruments are created, it is almost impossible to withdraw these measurements. It becomes more complicated when policymakers are directly influencing the industry structure by a net of organizational units to regulate waste streams. A forceful example of this kind of policy is the German DSD system that was created in the early 1990's [5].

\subsection{Evaluate the effectiveness of some economic instruments}

\subsubsection{Taxes}

The tax on resources will finally increase $R C p$ via $P m$. Recyclers can possibly attain higher profits by increasing $R C p$. High price of raw materials might awake awareness of waste prevention and encourage reuse or recycling on site. However, increase in total cost of real estate from tax will eventually be transformed into purchase cost of buildings.

Increase in $D f$ from tax on disposal fee of landfill also can encourage waste producers to carry waste into recycling or reuse. Recyclers also can enhance gate fee $G f$ up to meet critical condition: $T l+D f>T r+G f+E r$. To minimize pollution from landfill, income from tax might provide partial money to build the additional equipments of landfill leachate and gas collection system. Nevertheless, inappropriate level of tax and lack of recycling industry on nonprofit materials like aggregates will bring frequent illegal dumping.

\subsubsection{Subsidy}

The subsidy for recyclers is seen as contribution on total revenue of waste management. Recyclers and manufacture share this extra revenue. Subsidy becomes a flexible tool to compete with other rivals by mean of low $R C p$ and $G f$. Recyclers can survive in furious competition depending on government's support. Development of recycling market can benefit from subsidy for recyclers. Nevertheless, government must promise an attractive profit and acceptable payback period for private investors to drive the individual fund into 
recycling industry. The subsidy will undoubtedly place a great burden on limited financial expenditure of government. The consequent spurious quantity of recycling and illegal landfill without recycling should be banned by governmental supervision.

\subsubsection{Combination}

Tax on disposal fee and subsidy for recyclers will lead to increase in disposal price and direct revenue of recyclers. The soft increase of combination will be easily accepted by actors. Moreover, revenue from tax can supply financial expenditure from subsidy in the "reservoir" of governmental money. The tax on disposal fee and resource also can be applied, because the combination can increase disposal price and raw materials price for economic feasibility of recycling at the same time. Meanwhile, the consequent high cost for supervision need be realised, since government will spend a lot of time and money to enforce these instruments and evaluate the final impact on management system. Additionally, the high punishment must be come into practise in order to prevent illegal activities like illegal dumping or spurious quantity of recycling.

\subsubsection{Results and discussion}

Although tax is a high efficiency tool to control disposal cost, it will lead to a series of problems like frequent illegal dumping before recycling chains established. Concerning subsidy for recyclers, development of recycling market can benefit from it, as subsidy place a great burden on limited financial expenditure of government. Their combination might be an appropriate solution if high supervision cost of government is reduced for illegal dumping and fictitious production of recycled materials. In order to reduce the supervision cost, technical and treatment regulations as assistant should be considered because of flexible enforcement and convenient supervision compared with economic instruments. A process of integrated waste strategy should be considered:

1). Subsidy for fostering recycling industry. Recyclers can survive in furious competition depending on direct revenue from government in the beginning of recycling market. Meanwhile, related technical regulations and utilization standard of recycled materials should be explored. Potential demand market for recycled materials like aggregates need be further exploited.

2). Combination to lighten financial burden by mean of tax revenue. Moreover, revenue from tax can supply financial expenditure from subsidy in the "reservoir" of governmental finance. In addition, technical regulations on landfill may be applied to further reduce subsidy by increasing disposal cost of landfill.

3). Tax with comprehensive regulation system. Tax can be implemented, while recyclers have enough power to compete with other rivals without subsidy. Comprehensive regulation and supervision net will insure execution of tax. Treatment regulations also can be considered to substitute for function of tax on landfill at this stage.

4). Self-determination of recycling market. Self-determination of recycling market will come in case of: ${ }^{1)}$ increase in the tipping fee of landfill caused by both the overall decrease in the amount of landfill space and the increasing costs 
of managing landfills; ${ }^{2)}$ increase in prices of raw material from the amount decrease. Namely, the operational cost of landfill and the production cost of raw materials are high enough to support the recycling cost of recyclers.

\section{Conclusion}

The current recycling market causes that only small amounts of valuable materials like copper and steel are reused or recycled, whereas large amounts of materials like concrete are directly transported into the C\&D landfills, because no profit can be made out of recycling in today's economic environment. To find out effective approaches to recycling non-profit waste, this paper outlines the trend of C\&DW generation in China and explains problems of current waste management. Economics has to take the leader in order to design and maintain effective waste management structures by analyzing the interaction among actors. A process of integrated waste strategy should be considered based on analysis of respective strength and weakness of government instruments: Subsidy for fostering recycling industry $\rightarrow$ Combination to lighten financial burden by revenue of tax $\rightarrow$ Tax with comprehensive regulation system $\rightarrow$ Selfdetermination of recycling market.

\section{References}

[1] Chen, H., Ganesan, S. \& Jia, B., Environmental challenges of post-reform housing development in Beijing. Habitat International, 29, pp. 571-589, 2005.

[2] Chui, D., Yang, Z., C\&D waste recycled for development of economic cycle, Industry Technologic Economy, 110 (25), pp. 355-359, 2006.

[3] National Statistic Agency of China. China Statistic Yearbook, China Statistic Publishers: Beijing, 1998-2007.

[4] Wang, J., Kang, X., Shen, L. \& Tan, Y., Research on management measures for reducing construction waste, Architecture Technology, 5(35), pp.799805, 2004.

[5] Leeftink, R., Money in the Waste-Inverse Economics in Artificial Arenas, ISWA World Congress, Amsterdam, pp. 1-12, 2007. 